\title{
Mechanical behaviour of the cellulosic dielectric materials of windings in power transformers in operation
}

\author{
C. Oria, A. Ortiz, I. Fernández, I. Carrascal, D. Ferreño
}

\begin{abstract}
Power transformers are crucial elements in electrical systems, and the end of their useful life is commonly conditioned by the degradation of the cellulosic insulation materials inside them. These materials are subjected to elevated temperatures and mechanical stresses, generated by electrical solicitations which deform the copper conductors and subsequently the paper, and also to the chemical reactions which take place in the dielectric oil in which the paper is impregnated. In order to better understand the behaviour of cellulosic insulation, we have studied the previous bibliography analysing the mechanical behaviour of cellulosic materials. At present, there are no experimental results analysing how the paper responds to the deformation suffered by the copper conductor in a realistic situation. We have developed a simulation model describing the mechanical behaviour of a standardised copper conductor wrapped with four layers of dielectric paper, using ANSYS Workbench Static Structural, which will be compared with experimental results afterwards.
\end{abstract}

Index Terms-- Ageing; paper insulation; computational modelling; elastoplasticity; oil insulation; power transformers; strain; stress; tensile strength

\section{INTRODUCTION}

Nowadays, electric utilities are focusing their efforts on reducing operating costs, reinforcing the reliability of transmission and distribution equipment, and enhancing quality of power and services to the customer. Specifically, power transformers are considered to be one of the most significant elements in the transmission and distribution of electricity, because of the substantial investments in these devices and their crucial influence on the reliability of the system, as unexpected interruptions of service due to any kind of failure can be catastrophic.

The windings are among the most vulnerable parts of the transformer, and they are made of conductors which are covered with insulating paper. Other components of the transformer, such as pressrings, pressplates or spacers, are made of board materials (paperboard or pressboard). These cellulose based components are necessary not only to ensure a high dielectric strength, but also for mechanical purposes, as paper combines good insulating properties with the necessary mechanical stability, needed to ensure strength against the mechanical forces arising from inrush currents or short-circuits.

The most frequently used cellulosic insulation is Kraft paper, impregnated with oil, which provides both insulation and cooling. The complex and irreversible degradation of these cellulosic materials is usually the main reason for the end of life of the transformer, causing its failure through

Financial support should be acknowledged here. Example: This work was supported in part by the U.S. Department of Commerce under Grant BS123.

C. Oria, A. Ortiz and I. Fernández are with the Electrical and Energy Department, University of Cantabria, Avda. de los Castros, 46. 39005, Santander, Spain, (e-mail: carmela.oria@unican.es).

I. Carrascal and D. Ferreño are with the Laboratory of Science and Engineering of Materials, University of Cantabria, Avda. de los Castros, 46. 39005, Santander, Spain, (e-mail: isidro.carrascal@unican.es).

\section{diverse mechanisms.}

\section{A. Mechanical behaviour of paper materials}

Paper is often considered an orthotropic material, as the three main directions of the paper machine can be approximately considered as the principal directions of the material: the machine direction (MD), the cross-machine direction (CD), and the through-thickness direction (ZD).

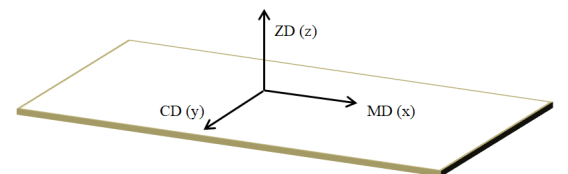

Fig. 1. Principal directions of paper material.

Paper materials show a highly anisotropic behaviour which is mainly due to the manufacturing and drying processes. The shear forces which develop in those processes ensure that more fibre axes are aligned parallel with (in MD) than perpendicular (in CD) to the flow of the paper through the paper machine, and nearly no fibres are directed in the through-thickness direction. In all cellulose-based products the stiffness in MD is usually $1-5$ times greater than that in $\mathrm{CD}$, and typically 100 times greater than that in ZD.

A sheet of paper is composed of fibres, which are in turn composed of fibrils, made of cellulose chains, which are oriented at an angle to the axis of the fibre and embedded in a matrix of hemicellulose. According to [1], cellulose fibres can be described as slender and kinked beams with high tensile stiffness and strength along their axis. The cellulosehemicellulose, which is assumed to be orthotropic, is embedded in lignin, which is assumed to be isotropic. The mechanical behaviour of a paper sheet depends on the fibre, fibre-fibre bond properties, and the geometrical structure of the bonded fibrous network, according to [2]. The elastic behaviour of the fibre depends on many factors related to the constituent properties of the cellulose, hemicellulose and lignin components of the cell wall, as well as its structure and the existence of damaged zones. The cellulose elastic properties are assumed to be independent of moisture content, whereas the hemicellulose and lignin properties are dependent on the moisture content.

As cellulose and hemicellulose are polymers, they show creep deformations, especially accelerated by temperature and moisture, when subjected to the long-term application of mechanical loads, which are caused by the internal rearrangement mechanism of the polymeric chains and influences both the in-plane and the out-of-plane mechanical behaviour.

\section{B. Analysis of the previous bibliography regarding the} mechanical behaviour of dielectric cellulosic materials

In conclusion, paper materials generally are complex materials to model due to their highly anisotropic behaviour, non-linear material response, rate sensitivity and dependency on the moisture content of the material. Due to their strong anisotropy, isotropic material models do not generally give sufficiently good results for most applications [2]. 
The existing bibliography has been reviewed and classified in Table I, obtaining the following conclusions:

- There are few studies on models that analyse the mechanical behaviour of cellulosic dielectric material and how the thermal and electrical stresses affect their ageing.

- Most of the existing models are focused on the behaviour of board materials (paperboard or pressboard) and there are very few which analyse the paper insulation wrapped around the conductors.

- The mechanical behaviour of these cellulosic materials has been considered as elastoplastic in most cases. In other analyses, it has been considered as viscoelastic or viscoplastic. It is not usual to consider the behaviour as elastic, as it has been established that that assumption is not realistic.

- Several authors have developed elastoplastic and viscoelastic computational models, with various levels of complexity and based on different hypothesis and simplifications. These models have been implemented into a FE software and the numerical results have been compared with the experimental results, with a considerably good agreement in some cases.

- Although some authors consider the influences of moisture and cyclic stress, it has not been completely understood, nor how paper and dielectric oil interact or if the use of different types of oil have any influence.

- At present, there are no experimental results analysing the mechanical behaviour of cellulosic dielectric material in a realistic situation, and how it responds to the deformation suffered by the copper conductor.

\section{TECHNICAL WORK PREPARATION}

\section{A. Continuously Transposed Conductors (CTC)}

Continuously Transposed Conductors (CTC) are often used in power transformers and consist of a variable number of enamel coated rectangular copper strands made into an assembly, arranged in two stacks to transpose the strands, and covered with several layers of insulating paper. CTCs have some advantages: they reduce both eddy currents and voltage losses, and they decrease the size and cost of transformer.

Because there are previous references which analyse some aspects of the performance of a CTC from a mechanical point of view (such as [3], [4] or [5]) and there is also an interest from manufacturers on improving the understanding of the degradation processes which could lead to the end of life of transformers, we are focusing in extending those analyses. In particular, we will study a real commercial CTC conductor with its insulating paper, which can be seen in Fig.2.

\section{B. Simulation model}

According to a previous study from [4], electromagnetic forces inside power transformers result from the combination of leakage flux and current density through the windings. The electromagnetic force vector $F$, with respect to the cylindrical coordinate system of a coil, is defined according to equation,

$$
F=L \cdot I \times B=\left(\begin{array}{c}
F_{r} \\
F_{\varphi} \\
F_{z}
\end{array}\right)=L\left(\begin{array}{c}
I_{\varphi} B_{z} \\
0 \\
-I_{\varphi} B r
\end{array}\right)
$$

Where $B$ is the leakage flux vector, $I$ is the current vector and $L$ is the winding length.

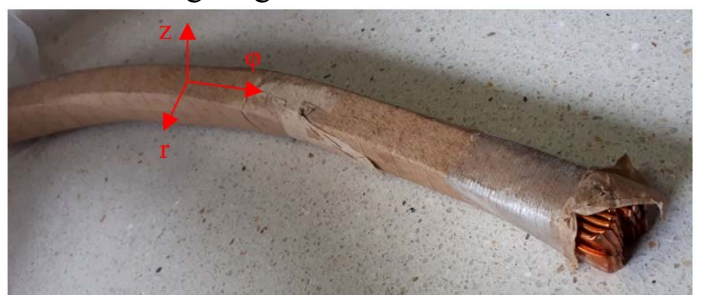

Fig. 2. Real CTC conductor which will be analysed in the laboratory with its cylindrical coordinate system.

The most critical component of that force vector is $F_{r}$, because the bending stiffness of a CTC is much lower in radial than in axial direction. Because of that, in our work we consider a radial short-circuit force happening in the transformer which will produce shear and normal stresses in the surrounding paper layers. This force will be represented in a laboratory bending test for a sector of conductor wrapped in insulating paper.

The mechanical behaviour of that standardised copper conductor wrapped with four layers of dielectric paper has been modelled using ANSYS Workbench Static Structural. The simulation model attempts to reproduce the experimental analysis which we are going to develop in the laboratory using a real conductor, considering different ageing conditions for the cellulosic material impregnated in dielectric oil, and the experimental results will be compared to the simulation results. Although the real conductor has curvature, it has been neglected in the initial model for simplicity, analogously to in [4], where the authors

TABLE I

DifFERENT Models Proposed IN THE BIBLIOGRAPHy AND THE DiRECTIONS OF THE MATERIAL THAT THEY CONSIDER IN THE ANALYSIS

\begin{tabular}{|c|c|c|c|c|c|c|c|c|c|c|c|c|c|c|c|c|}
\hline & \multicolumn{4}{|c|}{ ELASTIC } & \multicolumn{4}{|c|}{ VISCOELASTIC } & \multicolumn{4}{|c|}{ VISCOPLASTIC } & \multicolumn{4}{|c|}{ ELASTOPLASTIC } \\
\hline & & MD & CD & ZD & & MD & CD & ZD & & MD & CD & ZD & & MD & CD & ZD \\
\hline $\begin{array}{c}\text { GENERIC POLYMERIC } \\
\text { MATERIALS }\end{array}$ & & & & & $\begin{array}{l}6] \\
{[7]}\end{array}$ & \multicolumn{3}{|c|}{ isotropic } & [7] & \multicolumn{3}{|c|}{ isotropic } & & & & \\
\hline PAPER & [8] & $\mathrm{x}$ & $\mathrm{x}$ & & $\begin{array}{c}{[9]} \\
{[10]} \\
{[11]}\end{array}$ & $\mathrm{x}$ & $\mathrm{x}$ & & $\begin{array}{l}{[12]} \\
{[11]}\end{array}$ & $\mathrm{x}$ & $\mathrm{x}$ & & [4] & & otropi & \\
\hline & & & & & [13] & $x$ & $\mathrm{x}$ & $\mathrm{x}$ & [13] & $x$ & $x$ & $\mathrm{x}$ & $\begin{array}{l}{[14]} \\
{[15]} \\
{[16]} \\
{[17]}\end{array}$ & $\mathrm{x}$ & $\mathrm{x}$ & $\mathrm{x}$ \\
\hline $\begin{array}{l}\text { BOARD MATERIALS } \\
\text { (Paperboard or Pressboard) }\end{array}$ & & & & & & & & & $\begin{array}{l}{[18]} \\
{[19]} \\
{[20]} \\
{[21]} \\
{[22]}\end{array}$ & & & $\mathrm{x}$ & $\begin{array}{c}{[23]} \\
{[24]} \\
{[25]} \\
{[26]} \\
{[1]} \\
{[27]} \\
228]\end{array}$ & & & $\mathrm{x}$ \\
\hline
\end{tabular}


considered that the big winding diameters of large power transformers and the high number of supporting sticks result in a negligible curvature. However, this hypothesis will be evaluated comparing the mechanical behaviour of the model and the experimental results measured in the laboratory after the bending test.

The geometry of the copper conductor is represented with a flexible solid prism in the model, with a length of $120 \mathrm{~mm}$, rectangular cross-section with dimensions of $22 \mathrm{~mm} \times 15.2$ $\mathrm{mm}$ and considering nonlinear effects. The conductor is wrapped in four layers of dielectric insulating paper also represented as flexible solid elements in the model, whose thickness is $80 \mu \mathrm{m}$. This cellulosic material is anisotropic in its mechanical behaviour, and it has a different value of the Young modulus in the MD and CD. However, for simplicity of the model, instead of defining an anisotropic material with a local coordinate system, an average value of the Young modulus is used, as the contribution of the paper material in the mechanical resistance of the whole conductor is negligible, and we are only interested in the deformation that the paper is going to suffer as a result of wrapping the deformable copper conductor. The material properties of the paper material are obtained from laboratory tests for different levels of ageing (detailed in part $\mathrm{C}$ ) and introduced in the numerical model.

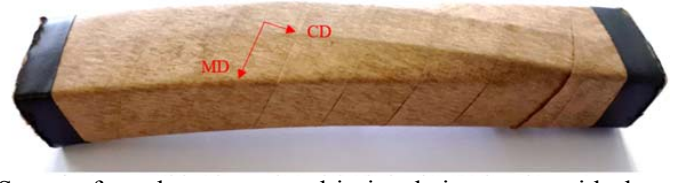

Fig. 3. Sector of conductor wrapped in insulating paper with the principal directions of the cellulosic material, MD and CD.

The prismatic copper conductor is supported on two rigid cylinders made of structural steel, to the bases of which two remote displacements have been applied and all degrees of freedom have been impeded: X, Y, Z, Rotation X, Rotation Y and Rotation $Z$ have been set to 0 . Another rigid cylinder has been used to apply a load in direction -Y (modelled as a remote force) on the copper conductor. In the base of this third cylinder, a remote displacement has been applied impeding all the degrees of freedom except the Y Component which is set as "Free".

The contacts between adjacent layers of paper, as well as the contact between the copper core and the first layer have been modelled as bonded, with Augmented Lagrange formulation, and a normal stiffness factor of 100 (with an update of the stiffness in each iteration, aggressive) in order to avoid penetration between the thin layers of insulating paper and the copper core. Furthermore, the contacts between the cylinders and the conductor have been modelled as bonded with Multi-Point Constraint (MPC) formulation. The paper layers are meshed with sufficiently fine elements to capture the mechanical behaviour, and smaller elements have been used in the zones which are going to be subjected to higher stresses (Fig. 4), near the contacts between the prism and the rigid cylinders, through a body sizing of $0.25 \mathrm{~mm}$.

The relevant results in the model will be the total and directional deformation, and the equivalent (von-Mises) stresses in the different layers of insulating paper, as the purpose of this research is to identify when the paper material is subjected to the maximum tensile stress that it can withstand, $\sigma \max (\mathrm{MPa})$. After the maximum stress, a failure mechanism, such as entering in the plastic-zone or even fracture due to stress concentrations, could start in the material and that would have an influence on the end of the useful life of the power transformer.

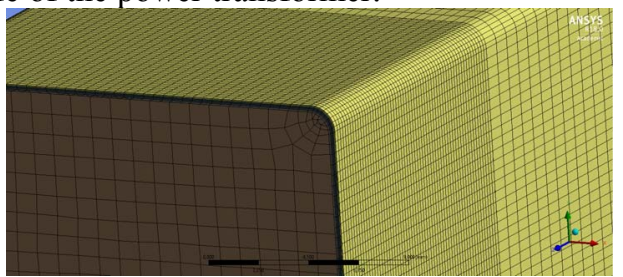

Fig. 4. Close view of the mesh for the paper layers and for the copper core.

\section{Experimental work}

The purpose of this experimental work is to characterise the cellulosic material in which the copper conductor is wrapped, under different ageing states, in order to introduce its properties into the simulation model. The paper has been aged isothermally in temperature-controlled ovens in the laboratory during different time periods. When the ageing process is finished, the stress-strain curves up to failure have been obtained in the laboratory for each ageing state.

With the previously developed simulation model, it will be possible to obtain the vertical force which represents the effect of a short-circuit and must be applied in the upper rigid cylinder to produce the maximum stress that the paper material can withstand for each ageing state.

Twelve test pieces, with the same geometry as that introduced into the model, have been obtained from the copper coil and have been vacuum-dried in an oven at $100^{\circ} \mathrm{C}$ for 3 hours to reduce their moisture content. After this preconditioning process, the final moisture content has been measured using the Karl-Fischer titration method (KF) and was equal to $1.99 \%$. After that, the test pieces have been aged isothermally in temperature-controlled ovens in the laboratory, considering the following ageing states:

- STATE 0: Four test pieces are not aged

- STATE I: Four test pieces are impregnated in dielectric oil and aged for a week at $150^{\circ} \mathrm{C}$

- STATE II: Four test pieces are impregnated in dielectric oil and aged for four weeks at $150^{\circ} \mathrm{C}$

Two sealed vessels filled with dielectric mineral oil have been used, and four samples have been introduced in each of the vessels. After that, the vessels have been vacuum-sealed. Finally, before introducing the two vessels into the oven in order to start the ageing process of the samples, an inert atmosphere has been created by introducing nitrogen in the free space which was created in the vessel after the removal of air.

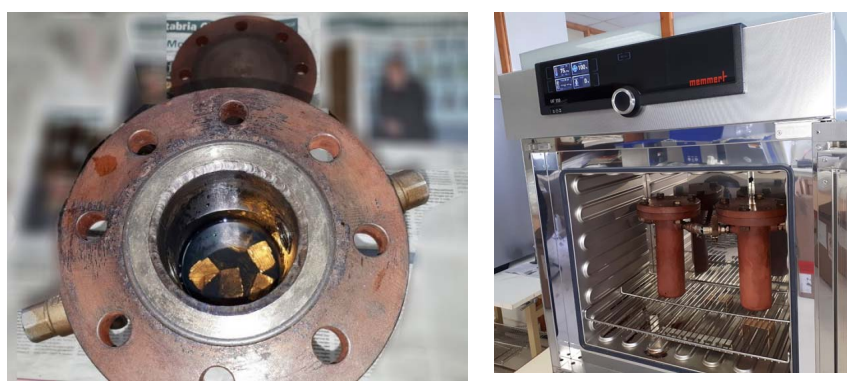

Fig. 5. (a) Test pieces in the vessel filled with dielectric oil; (b) Vessels containing the oil-impregnated samples being introduced in the convective oven to start the ageing process. 
Once the ageing process has finished, the insulating paper in which the conductor is wrapped has been extracted from one test piece of each of the ageing states. We have distinguished from which layer each paper sample is obtained, and two samples from each layer were extracted to perform a tensile test and measure material properties in MD.

The Standard ISO 1924-2 "Determination of tensile properties" specifies a method for the measurement of tensile strength, elongation to break, energy absorbed by paper and paperboard and tensile stiffness in which the test equipment is operated with a constant speed of elongation $(20 \mathrm{~mm} /$ min). In that method, the jaws of the tensile testing machine must be placed so that the average distance between the fixing lines is $(180 \pm 1) \mathrm{mm}$ and the specimens must have a width of $(15 \pm 0.1) \mathrm{mm}$. In some circumstances, such as when the product has limited size, a smaller test length can be used, but it must be long enough to be fixed between the jaws.

Here, in the tensile test for the characterisation of the material in MD, the dimensions of the paper sample were 140 $\mathrm{mm} \times 15 \mathrm{~mm}$, because it was the only way in which we could obtain two paper samples from each layer. A speed of elongation of $20 \mathrm{~mm} / \mathrm{min}$ was used. The paper samples were numbered starting from the layer in contact with the copper conductor (Layer 1) up to the most external layer (Layer 4), and 24 paper pieces were tested ( 3 ageing states $\mathrm{x} 4$ paper layers in each copper conductor piece $\mathrm{x} 2$ paper pieces for each layer).

From the results of the tensile tests, it can be seen that a paper material whose mechanical properties radically differ has been used by the manufacturer in the internal layers (1 and 2) and in the external layers (3 and 4). The first one behaves as a plastic material, while the second one behaves as a hyperelastic one. The comparison between the behaviour of the two specimens obtained from the same layer and ageing state is summarised in Table II. It can be seen that the tensile strength of the external layers is, in most tests, slightly higher than in the internal ones, but especially the strain at fracture is much greater in layers 3 and 4 than in the internal ones.
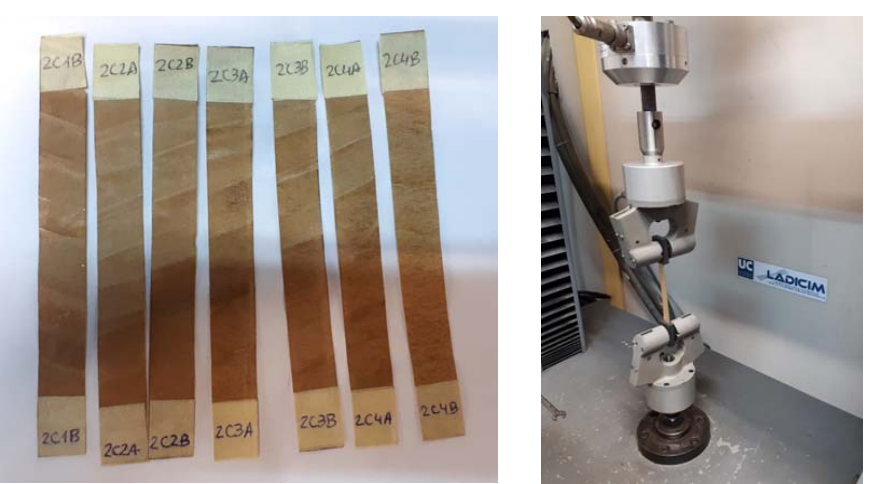

Fig. 6. (a) Some paper samples of Ageing State II; (b) Tensile test for the characterisation of the paper samples in MD.

The high degree of heterogeneity of the material is one of its main features and is mainly due to its microstructure and local defects such as microcracks or small delaminations. For example, in Ageing State 0, that is especially obvious in layer 4; in Ageing State I, in layers 3 and 4; and in Ageing State II, in layer 3. For each layer and ageing state, the stress-strain obtained in the tensile test which gave a higher tensile strength has been introduced in the numerical model, as it is considered to be more representative of the mechanical behaviour of the material without local defects. The plasticity of layers 1 and 2 was defined in the numerical model through Multilinear Kinematic Hardening, and the hyperelastic experimental data of layers 3 and 4 were introduced.

In Fig. 7-10, the results of the tensile tests are shown for the same layer and different ageing states. It must be noted that layer 1 was quite deteriorated in the extraction before the tests after the ageing process at $150^{\circ} \mathrm{C}$, because it was glued to the copper conductor and it suffered local delaminations. Thus, the reduction in stiffness of layer 1 in ageing states I and II is not representative of the real behaviour of the material.

In layers 2, 3 and 4, an unexpected result was obtained: the strength seems to be slightly higher in Ageing State I than when the paper sample is not aged. The reason could be that the initial impregnation of dielectric oil filling the voids in the paper material produces an improvement of the mechanical resistance in comparison with the factory new paper. However, after four weeks of ageing at $150^{\circ} \mathrm{C}$ (Ageing

TABLE II

RESULTS OF TENSILE TESTS IN THE DIFFERENT SAMPLES IN MD.

\begin{tabular}{|c|c|c|c|c|c|c|c|c|}
\hline \multirow[t]{2}{*}{ Ageing state } & \multicolumn{8}{|c|}{ STATE 0 (Not aged) } \\
\hline & \multicolumn{2}{|c|}{ Layer 1} & \multicolumn{2}{|c|}{ Layer 2} & \multicolumn{2}{|c|}{ Layer 3} & \multicolumn{2}{|c|}{ Layer 4} \\
\hline Sample & $0 C 1 A$ & $0 C 1 B$ & $0 C 2 A$ & $0 C 2 B$ & $0 C 3 A$ & $0 C 3 B$ & $0 C 4 A$ & $0 C 4 B$ \\
\hline Young's Modulus, E0 MD $(\mathrm{GPa})$ & 5.577 & 5.697 & 6.767 & 5.651 & 1.870 & 2.207 & 2.865 & 2.047 \\
\hline Tensile strength, $\sigma_{\max }(\mathrm{MPa})$ & 75.33 & 80.25 & 77.42 & 60.167 & 81.67 & 92.00 & 96.58 & 24.58 \\
\hline Strain at break $(\%)$ & 2.12 & 2.41 & 2.21 & 1.67 & 15.55 & 17.03 & 15.97 & 9.54 \\
\hline \multirow{2}{*}{ Ageing state } & \multicolumn{8}{|c|}{ STATE I (Aged for a week at $\left.150^{\circ} \mathrm{C}\right)$} \\
\hline & \multicolumn{2}{|c|}{ Layer 1} & \multicolumn{2}{|c|}{ Layer 2} & \multicolumn{2}{|c|}{ Layer 3} & \multicolumn{2}{|c|}{ Layer 4} \\
\hline Sample & $1 C 1 A$ & $1 C 1 B$ & $1 C 2 A$ & $1 C 2 B$ & $1 C 3 A$ & $1 C 3 B$ & $1 C 4 A$ & $1 C 4 B$ \\
\hline Young's Modulus, E0 MD $(\mathrm{GPa})$ & 6.076 & 5.969 & 7.628 & 6.004 & 1.923 & 2.790 & 3.051 & 1.775 \\
\hline Tensile strength, $\sigma_{\max }(\mathrm{MPa})$ & 46.00 & 58.67 & 80.25 & 58.92 & 96.42 & 31.33 & 111.83 & 32.75 \\
\hline Strain at break $(\%)$ & 0.99 & 1.45 & 1.79 & 1.30 & 15.08 & 8.41 & 16.74 & 10.72 \\
\hline \multirow[t]{2}{*}{ Ageing state } & \multicolumn{8}{|c|}{ STATE II (Aged for four weeks at $150^{\circ} \mathrm{C}$ ) } \\
\hline & \multicolumn{2}{|c|}{ Layer 1} & \multicolumn{2}{|c|}{ Layer 2} & \multicolumn{2}{|c|}{ Layer 3} & \multicolumn{2}{|c|}{ Layer 4} \\
\hline Sample & $2 C 1 A$ & $2 C 1 B$ & $2 C 2 A$ & $2 C 2 B$ & $2 C 3 A$ & $2 C 3 B$ & $2 C 4 A$ & $2 C 4 B$ \\
\hline Young's Modulus, E0 MD (GPa) & 7.127 & 5.381 & 7.438 & 6.647 & 2.276 & 2.074 & 2.069 & 1.893 \\
\hline Tensile strength, $\sigma_{\max }(\mathrm{MPa})$ & 42.08 & 33.08 & 58.75 & 63.00 & 81.92 & 38.50 & 80.83 & 68.25 \\
\hline Strain at break $(\%)$ & 0.67 & 0.71 & 1.24 & 1.45 & 14.14 & 9.23 & 14.92 & 14.13 \\
\hline
\end{tabular}


State II), the mechanical resistance of the material diminished.

Moreover, the characterisation of the material in $\mathrm{CD}$ has been performed in some paper samples of Ageing State 0 . The paper samples had an average length of $17.06 \mathrm{~mm}$ and an average width of $15.86 \mathrm{~mm}$, because the insulating paper in which the copper conductor is wrapped is quite narrow and makes it complicated to extract larger samples for the characterisation in $\mathrm{CD}$. As the dimensions of the paper samples were remarkably different to those recommended in ISO 1924-2, a speed of elongation of $1.7 \mathrm{~mm} / \mathrm{min}$ was used, proportional to the normalised one and the length of the tested samples.

It can be seen in Fig. 11 that the Young's Modulus is considerably lower in $\mathrm{CD}$ than in $\mathrm{MD}$, in accordance with the revised bibliography. In Ageing State $0, \mathrm{E}_{0 \mathrm{CD}}$ is approximately $13.7 \%$ of $\mathrm{E}_{0 \mathrm{MD}}$ for layer 1 , about $17.3 \%$ of $\mathrm{E}_{0}$ MD for layer 2, about $27.9 \%$ of $\mathrm{E}_{0 \mathrm{MD}}$ for layer 3, and $22.6 \%$ for layer 4. However, the strain at fracture is much higher in $\mathrm{CD}$ than in MD, especially for the internal layers (1 and 2) and to a lesser extent for the external layers (3 and 4).

\section{Results}

Two different cellulosic materials which are used in a commercial CTC conductor have been tested in the laboratory under different ageing states, and the accused differences in their mechanical behaviour have been noticed. If the results of layer 2 are considered as representative of the plastic cellulosic material used the internal layers (as layer 1 was quite deteriorated in the extraction), the strain at break reduces approximately $44 \%$ between Ageing State $0(0.0221)$ and Ageing State II (0.01236). However, the reduction in tensile strength is not that marked, about $24.1 \%$, indicating that a longer ageing process should be consider in future analyses.

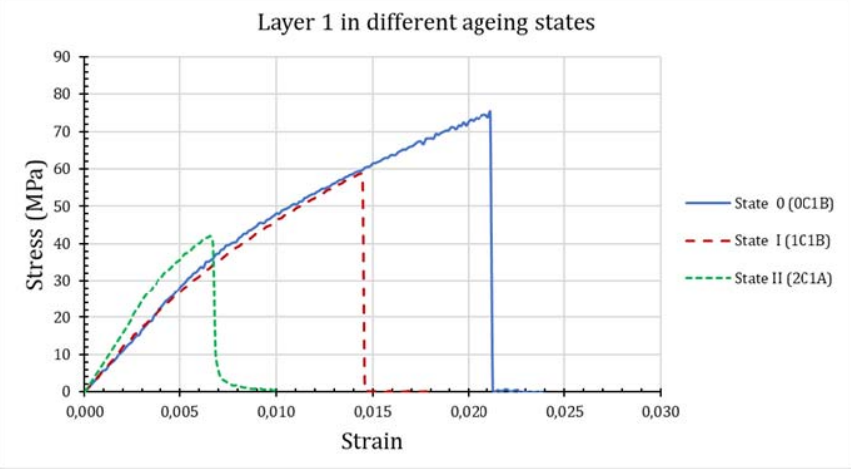

Fig. 7. Tensile test in MD for layer 1 in the different ageing states.

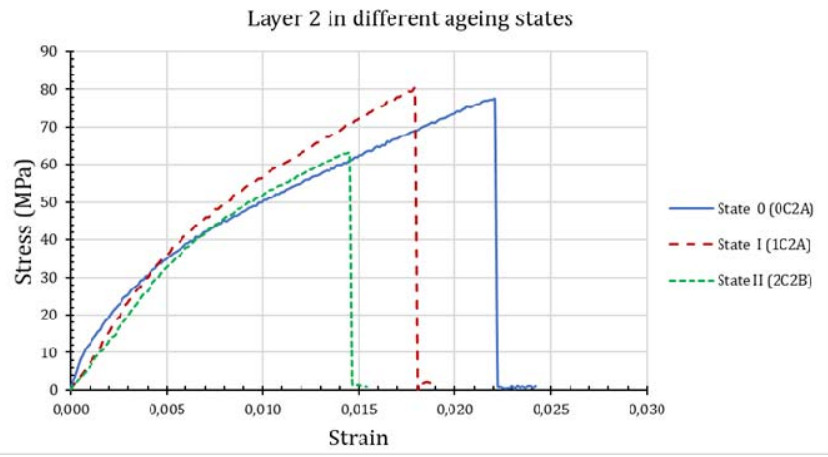

Fig. 8. Tensile test in MD for layer 2 in the different ageing states.

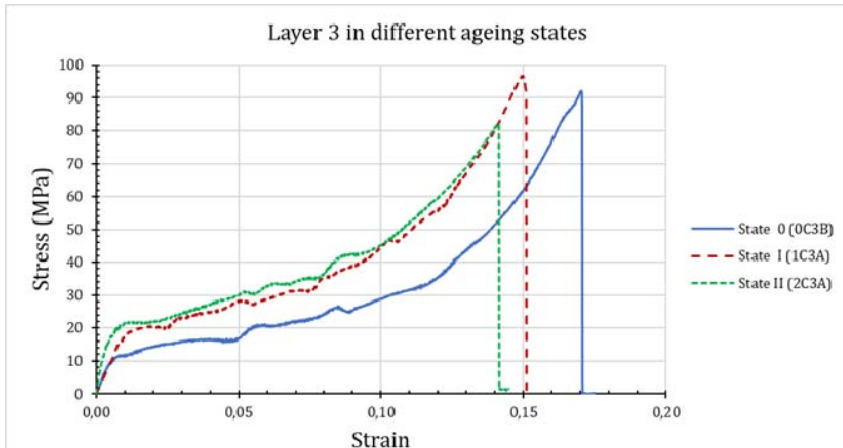

Fig. 9. Tensile test in MD for layer 3 in the different ageing states.

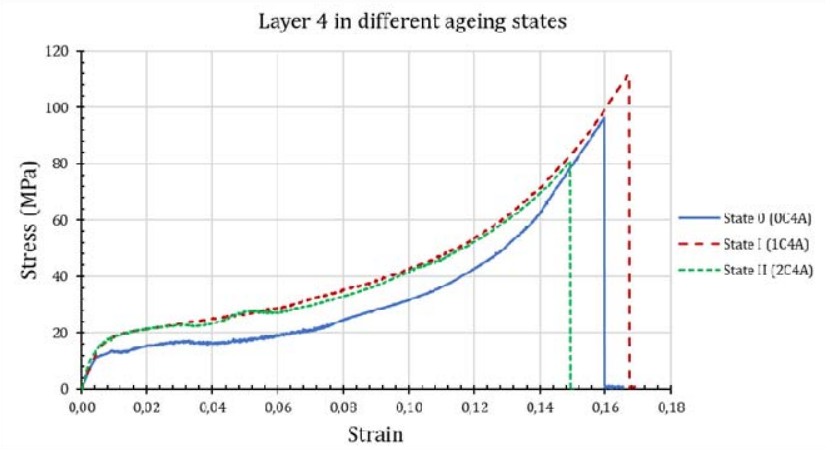

Fig. 10. Tensile test in MD for layer 4 in the different ageing states.

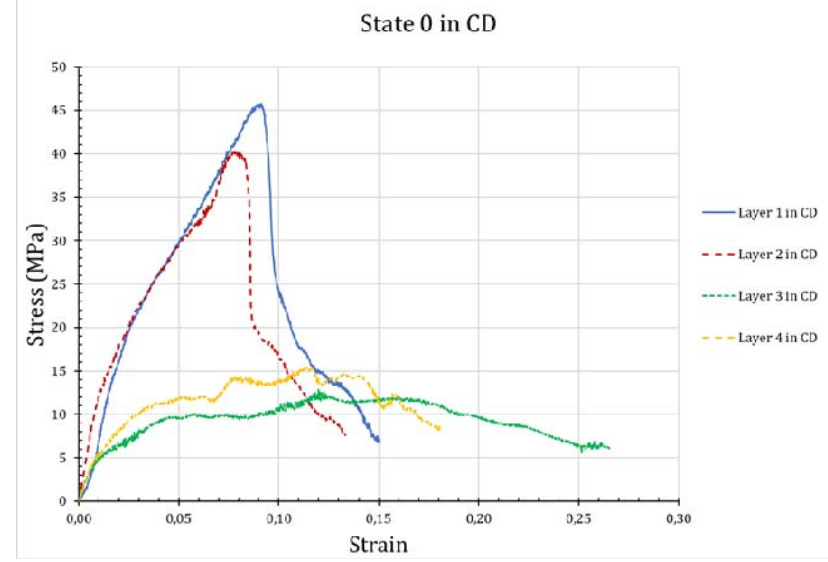

Fig. 11. Tensile test in CD for Ageing State 0 and the different layers.

Considering the average value of the strain at fracture for the external layers (3 and 4), and without taking into consideration the results of samples $0 \mathrm{C} 4 \mathrm{~B}$ and $2 \mathrm{C} 3 \mathrm{~B}$, in which a local defect should have caused a reduction in the mechanical properties, the strain at break reduces approximately $11 \%$ between Ageing State 0 (0.1618) and Ageing State II (0.1440). Consequently, the ageing process affects to a greater extent the strain at break of the plastic material than that of the hyperelastic one. Regarding the tensile strength of the hyperelastic paper, it reduces approximately $14.5 \%$ between Ageing State $0(90.08 \mathrm{MPa})$ and Ageing State II (77 MPa).

The analysis of the samples in CD showed that the tensile strength in this direction is much lower than in MD. In particular, the average tensile strength in $\mathrm{CD}$ in the internal layers $(43.08 \mathrm{MPa})$ is $41.2 \%$ lower than in $\mathrm{MD}$. For the external layers, this reduction is more dramatic and the average tensile strength in $\mathrm{CD}(13.57 \mathrm{MPa})$ is $84.9 \%$ lower than in MD. However, the strain at fracture in $\mathrm{CD}$ increases both for the material in the internal and external layers, being in the hyperelastic paper of the same order of magnitude than 


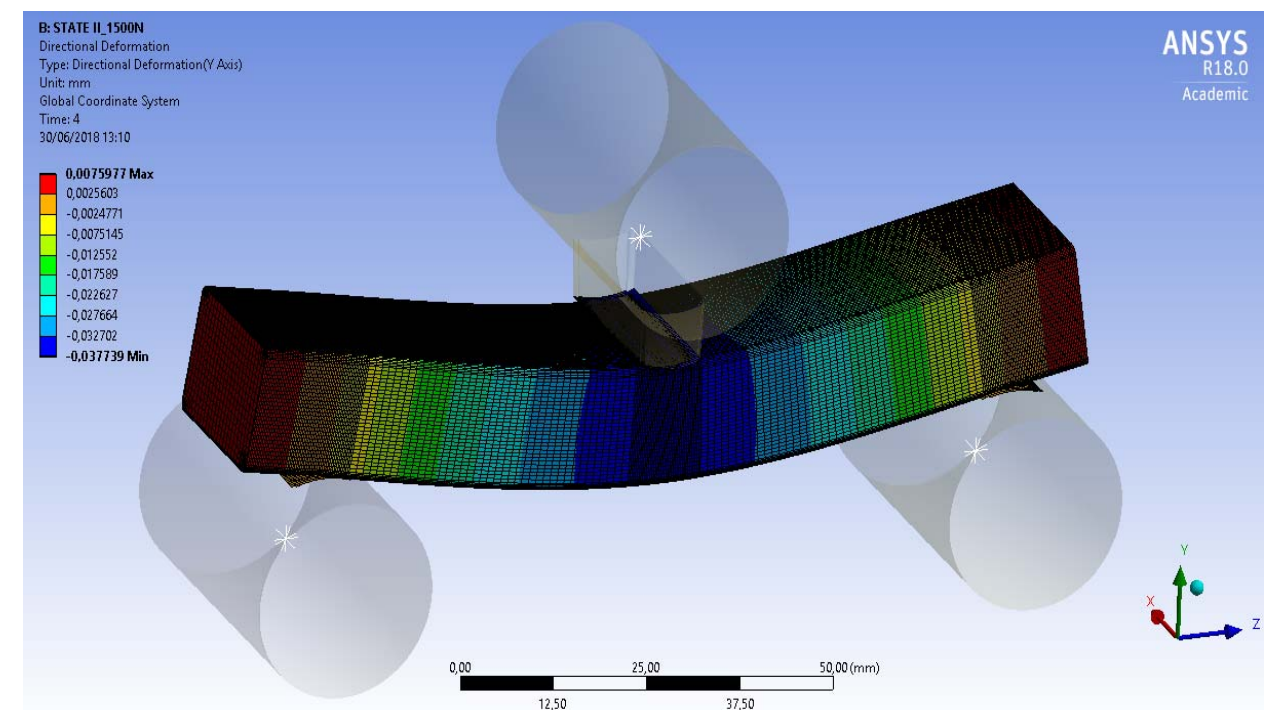

Fig. 12. Directional deformation of the copper conductor in Ageing State II as a result of an external applied force of $1500 \mathrm{~N}$.

the strain in MD and around 4 times greater in the plastic material.

These differences in the behaviour in MD and CD should be considered in the model, as any short-circuit or inrush current would produce a complex mechanical solicitation which would not be aligned with the main direction of the paper material.

The simulation model shows that the external layers suffer higher stresses than the internal ones, and that could have been the reason why a more resistant material was used in layers 3 and 4 in the manufacturing process. For example, when a vertical force of $1500 \mathrm{~N}$ is applied in the simulation model for Ageing State II (Fig. 12), there is a maximum equivalent stress in layer 4 of $65.916 \mathrm{MPa}$, while the maximum stress in layer 1 is equal to $27.97 \mathrm{MPa}$. Moreover, it is expected that the ageing process has a stronger impact on the external layers and for both reasons it is probable that the first defects that could lead to fracture in the paper material will happen in those layers.

\section{CONCLUSIONS}

The present study must be extended, and more ageing states must be considered, in order to analyse the performance of the material with an increased reduction in resistance, as four weeks of ageing have not produced a really significant decrease in the tensile strength. It will be also necessary to study the correlation between that decrease in mechanical properties and the reduction in the degree of polymerisation (DP) of the material, taking into consideration the real reduction in DP which happens in power transformers after years of operation.

Moreover, the aged copper test pieces wrapped in insulating paper must be subjected to a bending test in the laboratory, with a central static load analogous to the one which was introduced in the simulation model, to compare whether the results of the laboratory tests agree with the predictions of the simulation and the paper starts deteriorating at the predicted load level and if the fracture starts in layer 4 . If relevant differences are noticed between the model and these laboratory results, the model will be refined in order to accurately represent the mechanical behaviour of the material.

Another extension of this study that must be considered is to apply a cyclic load both in the simulation and in the laboratory, which would be a more realistic representation of a sinusoidal short-circuit current affecting the transformer windings. The deformation applied in the laboratory could be analogous to the one which is exemplified in [5].

In conclusion, this model is the first step in our aim to satisfactorily picture the real response of the copper conductor and the paper dielectric material, taking into consideration different ageing states and the influence of the insulating oil. With this contribution, we expect to clarify how the paper responds to the copper conductor deformation and how that phenomenon affects the lifetime and quality operation of power transformers.

\section{ACKNOWLEDGMENT}

The authors gratefully acknowledge the contribution of Ivo Fernández for his help with the preparation of the test pieces, and David John Cahill for his help in the revision of English language.

\section{REFERENCES}

[1] O. Girlanda et al, "Analysis of the Micromechanical Deformation in Pressboard performed by X-ray Microtomography," Electrical Insulation Conference (EIC), pp. 89, 2015.

[2] R. E. Mark et al, Ed., Handbook of Physical Testing of Paper (Volume 1). United States of America: Marcel Dekker, 2002

[3] D. Geissler and T. Leibfried, "Short circuit tests to derive the buckling strength of continuously transposed cable for power transformers under the influence of the paper insulation thickness," in Power Engineering Conference (UPEC), Cluj-Napoca, Romania, 2014

[4] D. Geissler and T. Leibfried, "Mechanical breakdown of aged insulating paper around continuously transposed conductors for power transformers under the influence of short-circuit forces - Analysis by numerical simulations," Electrical Insulation Conference (EIC), pp. 401, 2015.

[5] D. Geissler and T. Leibfried, "Short-Circuit Strenght of Power Transformer Windings-Verification of Tests by a Finite Element Analysis-Based Model," IEEE Transactions on Power Delivery, vol. 32, (4), 2017.

[6] H. T. Banks, S. Hu and Z. R. Kenz, "A Brief Review of Elasticity and Viscoelasticity for Solids," Advances in Applied Mathematics and Mechanics, vol. 3, (1), 2011.

[7] B. Miled, I. Doghri and L. Delannay, "Coupled viscoelastic-viscoplastic modeling of homogeneous and isotropic polymers: Numerical algorithm and analytical solutions," Computer Methods in Applied Mechanics and Engineering, vol. 200, pp. 3381, 2011.

[8] R. C. Neagu, E. K. Gamstedt and M. Lindström, "Characterization methods for elastic properties of wood fibers from mats for composite materials," Wood and Fiber Science, vol. 38, (1), pp. 95, 2006.

[9] J. Alfthan, "The Effect of Humidity Cycle Amplitude on Accelerated Tensile Creep of Paper," Mechanics of Time-Dependent Materials, vol. 8, pp. 289, 2004.

[10] J. Alfthan and P. Gudmundson, "Linear constitutive model for mechano-sorptive creep in paper," International Journal of Solids and Structures, vol. 42, pp. 6261, 2005.

[11] J. Alfthan, "Experimental study of non-linear stress relaxation and creep of paper materials and the relation between the two types of experiments," Nordic Pulp \& Paper Research Journal, vol. 25, (3), pp. 351, 2010.

[12] P. Mäkela, "The effect of moisture ratio and drying restraint on the stress relaxation of paper," in Gold Coast, Australia, 2007, pp. 169-177. 
[13] D. D. Tjahjanto, O. Girlanda and S. Östlund, "Anisotropic viscoelastic-viscoplastic continuum model for high-density cellulose-based materials," Journal of the Mechanics and Physics of Solids, vol. 84, 2015.

[14] P. Mäkela and S. Östlund, "Orthotropic elastic-plastic material model for paper materials," International Journal of Solids and Structures, vol. 40, pp. 5599, 2003.

[15] Q. S. Xia, M. C. Boyce and D. M. Parks, "A constitutive model for the anisotropic elastic-plastic deformation of paper and paperboard," International Journal of Solids and Structures, vol. 39, pp. 4053, 2002.

[16] A. Harrysson and M. Ristinmaa, "Large strain elasto-plastic model of paper and corrugated board," International Journal of Solids and Structures, vol. 45, pp. 3334, 2008.

[17] E. Borgqvist et al, "Distortional hardening plasticity model for paperboard," International Journal of Solids and Structures, vol. 51, pp. 2411, 2014.

[18] D. O. Swihart and D. V. Wright, "Dynamic stiffness and damping of transformer pressboard during axial short circuit vibration," IEEE Transactions on Power Apparatus and Systems, vol. 95, (2), pp. 721, 1976.

[19] O. Girlanda et al, "Influence of density on the out-of-plane mechanical properties of pressboard," in Conference on Electrical Insulation and Dielectric Phenomena (CEIDP) Proceeding, 2012, pp. 247.

[20] O. Girlanda et al, "Characterization and Modelling of the Mechanical Properties of Pressboard," Annual Report Conference on Electrical Insulation and Dielectric Phenomena, pp. 563, 2013.

[21] O. Girlanda et al, "Modeling and experimental validation of the mechanical behavior of pressboard," in 2014 IEEE Electrical Insulation Conference (EIC), Philadelphia, Pennsylvania, USA, 2014, .

[22] O. Girlanda et al, "On the transient out-of-plane behaviour of highdensity cellulose-based fibre mats," Journal of Materials Science, pp. 8131, 2016.

[23] N. Stenberg, C. Fellers and S. Östlund, "Plasticity in the thickness direction of paperboard under combined shear and normal loading ," Journal of Engineering Materials and Technology, vol. 123, (2), pp. 184, 2001.

[24] N. Stenberg, C. Fellers and S. Östlund, "Measuring the stress-strain properties of paperboard in the thickness direction," Journal of Pulp and Paper Science, vol. 27, (6), pp. 213, 2001.

[25] N. Stenberg, "A model for the through-thickness elastic-plastic behaviour of paper," International Journal of Solids and Structures, vol. 40, pp. 7483, 2003.

[26] M. Nygårds, "Modelling the out-of-plane behaviour of paperboard," Nordic Pulp \& Paper Research Journal, vol. 24, (1), pp. 72, 2009.

[27] T. Joffre et al, "A 3D in-situ investigation of the deformation in compressive loading in the thickness direction of cellulose fiber mats," Cellulose, vol. 22, (5), pp. 2993, 2015.

[28] O. Girlanda et al, "Static and quasi-static behavior of dry and oil-impregnated pressboard," in 2016 Electrical Insulation Conference (EIC), Montréal, Qc, Canada, 2016, pp. 105.

\section{BIOGRAPHIES}

Carmela Oria was born in Cantabria, Spain, on February 10, 1991. She received a M.Sc. degree in Civil Engineering from the University of Cantabria, Spain, in 2014. She is an Associate Professor and predoctoral fellow in the Electrical and Energy Department, University of Cantabria, under the supervision of Dr. Ortiz. Her field of research deals with the analysis of the mechanical behaviour of cellulosic dielectric materials.

Alfredo Ortiz received the M.Sc. degree in Industrial Engineering in 1997 and the Ph.D. degree in 2005 from the University of Cantabria (UC), Spain. $\mathrm{He}$ is an Associate Professor and the Head of Electrical and Energy Engineering Department at the UC. He has published six chapters in international books, over 50 works in international conferences and 30 papers in journals included in the Journal of Citation Report. Currently, his main research topic is the study of the dielectric system of power transformers.

Inmaculada Fernández received the M.Sc. degree in Chemical Engineering in 2004 and the Ph.D. degree in 2009 from the University of Cantabria (UC), Spain. Currently, she is Lecturer in the Electrical and Energy Engineering Department at the UC. Her main research topic is thermal ageing of insulation systems of power transformers.

Isidro A. Carrascal received the M.Sc. degree in Industrial Engineering in 1996 and the Ph.D. degree in 2006 from the University of Cantabria (UC), Spain. He is an Associate Professor and the Technical Manager of LADICIM (Laboratory of Science and Engineering of Materials of the University of Cantabria). He has published over 30 papers in journals included in the Journal of Citation Report. Currently, his main research topic is the Mechanical Behaviour and Characterisation of Materials.

Diego Ferreño received the M.Sc. degree in Civil Engineering in 1999 from the University of Cantabria (UC), the Master in Numerical Methods applied to Engineering in 2004 by the UPC, the Ph.D. degree in 2008 and the master's Degree in Physical Sciences in 2011 by the UC. As a researcher, he has participated in numerous competitive projects at regional, national and European level and has published over 30 papers in journals included in the Journal of Citation Report. His main lines of research are structural integrity of components, embrittlement by neutron irradiation in nuclear vessels, numerical simulation by finite elements, mechanical behaviour of biological materials and machine learning. 